\title{
Role of Adherens Junction Proteins in Differential Herpes Simplex Virus Type 2 Infectivity in Communication-Competent and-Deficient Cell Lines
}

\author{
Blair Miezeiewski Kerry McShane-Kay Richard I. Woodruff Gustave K.N. Mbuy \\ Maureen T. Knabb
}

Department of Biology, West Chester University, West Chester, Pa., USA

\section{Key Words}

HSV-2 • Gap junctions • Cx43 - WB cells • HeLa cells •

Adherens junctions

\begin{abstract}
Background: Gap junctional intercellular communication decreases with HSV-2 infection. To determine the importance of functional gap junctions for infectivity, we compared HSV-2 growth in communication-competent and -deficient cell lines. Methods: HSV-2 infectivity was tested in five cell lines: WB rat liver epithelial cells (communication-competent), WB-aB1 (communication-deficient), WB-a/32-10 (communication-rescued), HeLa (communication-deficient), and Cx43-transfected HeLa (communication-rescued) cells. HSV-2 growth curves and indirect immunofluorescence labeling of viral and cell proteins were performed in wild-type and mutant WB cells. Results: Although wild-type WB cells were highly permissive for HSV-2 infection, virus production was significantly attenuated in communication-deficient and -rescued mutant WB cells. HeLa exhibited no difference in infectivity between communication-competent and -deficient cell lines. Tight and adherens junction proteins, including zonula occludens-1 and nectin-1, were not different in the WB cell lines. However, E-cadherin levels were elevat-
\end{abstract}

ed and $\beta$-catenin was found to co-localize with glycoprotein E, a viral glycoprotein associated with cell-to-cell spread, in the mutant WB cells. Conclusions: These results suggest that attenuated viral production in mutant WB cells is due to viral protein co-localization with adherens junction proteins rather than the loss or restoration of functional gap junctions.

Copyright ๔ 2012 S. Karger AG, Basel

\section{Introduction}

Gap junctions, found in most animal tissues, are clusters of intercellular channels that directly link the cytoplasm of adjacent cells [1]. These channels usually mediate the transfer of low-molecular-mass $(\sim 1-2 \mathrm{kDa})$ ions and meTabolites between neighboring cells [2, 3], a process known as gap junctional intercellular communication (GJIC) [1]. More recently, larger molecular weight proteins have been found to permeate gap junctions in vertebrates [4].

Typically, in communication-competent cells such as Cx43-rich, WB-F344 rat liver epithelial (WB) cells, hundreds to thousands of gap junction channels cluster at membrane junctions to form plaques [5]. Following immunofluorescent labeling of $\mathrm{Cx} 43$ channel proteins, these

\section{KARGER}

Fax +41613061234

E-Mail karger@karger.ch

www.karger.com (c) 2012 S. Karger AG, Basel

$0300-5526 / 12 / 0556-0465 \$ 38.00 / 0$

Accessible online at:

www.karger.com/int
Maureen T. Knabb

Department of Biology

West Chester University

West Chester, PA 19383-8102 (USA)

Tel. +1 610436 2985, E-Mail mknabb@wcupa.edu 
Table 1. Summary of cell lines, functional gap junction communication, HSV-2 infectivity, and membrane protein distribution in this study

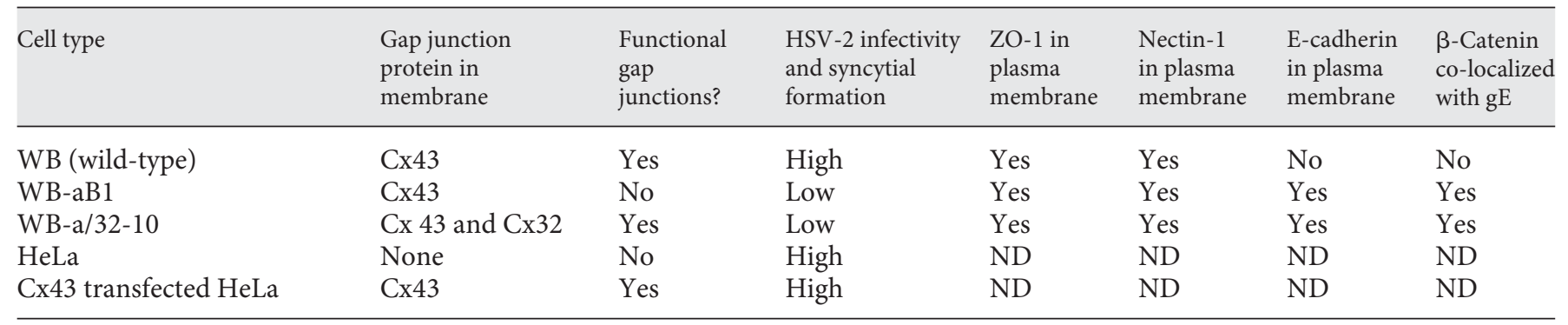

$\mathrm{ND}=$ Not done.

plaques appear as bright dots or dashes at cell-cell interfaces when viewed with a fluorescence light microscope [6]. In contrast, communication-deficient cell lines such as WB-aB1 (a mutant derivative of WB-F344 [7]), S180 mouse sarcoma [8] and L929 murine fibroblast cells [9] show a more uniform, less punctate distribution of $\mathrm{Cx} 43$ at membrane junctions. WB-aB1 cells, like S180 and L929 cells, express normal levels of $\mathrm{Cx} 43$ but do not possess the hyperphosphorylated form, Cx43-P2 [7]. The ability of cells to process $\mathrm{Cx} 43$ to $\mathrm{Cx} 43-\mathrm{P} 2$ has been strongly correlated to their ability to produce functional gap junctions $[10,11]$.

A number of effectors can alter the permeability and function of gap junction channels, such as cyclic nucleotides [12] and viral oncogene activity [13]. Following HSV-2 infection, GJIC is significantly attenuated by $6 \mathrm{~h}$ post-infection, before morphological changes are evident [14]. Although GJIC may be restored to near control levels when infected cells are treated with an antiviral compound [15], agents that block GJIC do not attenuate infectivity [16]. Stanton et al. [17] demonstrated that Cx43 is significantly downregulated in cytomegalovirus-infected fibroblasts even though these cells do not form gap junctions and $\mathrm{Cx} 43$ is localized in intracellular compartments. These conflicting results and the demonstrated reduction in GIC coincident with viral infection make it necessary to investigate the importance of functional gap junctions in virus infection.

To address this question, we tested HSV-2 infectivity in communication-competent and -deficient cell lines [7, $18,19]$. Communication-competent WB cells were highly permissive to HSV-2 infection while communicationdeficient WB cells were less permissive with reduced virus spread. However, both communication-competent and -deficient HeLa cells were highly permissive to HSV-
2 infection. The lack of a direct relationship between functional gap junctions and infectivity led to further exploration of the potential role of tight and adherens junction proteins to explain the difference in infectivity between mutant versus wild-type WB cells.

\section{Materials and Methods}

\section{Cells and Cell Culture}

Five cell lines were used in this investigation (Table 1): Fischer WB-F344 (WB, GJIC-competent) and WB-aB1 (aB1, GJIC-deficient) cells were a generous gift of Dr. James Trosko, Michigan State University; WB-a/32-10 (a/32-10, GJIC-rescued) cells were kindly provided by Dr. Randall Ruch, Medical College of Ohio, and HeLa cells (GJIC-deficient) and Cx-43-transfected HeLa cells (GJIC-rescued) were generously provided by Dr. Steven Scherer, University of Pennsylvania.

WB cells are rat liver epithelial cells that express Cx43 [18, 20] and carry out very efficient GJIC. WB-aB1 cells are GJIC-deficient mutants that express $\mathrm{Cx} 43$ but lack $\mathrm{Cx} 43-\mathrm{P} 2$, the hyperphosphorylated version of $\mathrm{Cx} 43$ [7]. WB-a/32-10 cells are WB-aB1 cells that have been sTably transfected to express the gap junction protein Cx32 in the presence of Geneticin (Invitrogen Corp., Carlsbad, Calif., USA) [18], which restores GJIC to these cells. WB and aB1 cells were propagated in $75-\mathrm{cm}^{2}$ tissue culture flasks in $\mathrm{D}$ medium (Gibco-BRL) supplemented with penicillin/streptomycin, pyruvate, glucose, $\mathrm{NaCl}, \mathrm{NaHCO}_{3}$ and $10 \%$ heat-inactivated newborn calf serum (HyClone), then incubated in a humidified atmosphere with $5 \% \mathrm{CO}_{2}$ in air at $37^{\circ}$. WB-a/32-10 cells were maintained as described above but with the addition of $0.4 \mathrm{mg} / \mathrm{ml}$ of Geneticin in D-medium to induce Cx32 expression.

HeLa cells were cultured in minimal essential medium (Gibco-BRL) containing $10 \%$ heat-inactivated newborn calf serum (HyClone), $5 \mathrm{U} / \mathrm{ml}$ penicillin, and $5 \mathrm{mg} / \mathrm{ml}$ streptomycin. Cx43transfected HeLa cells had puromycin $(0.5 \mu \mathrm{g} / \mathrm{ml})$ added to the media to induce $\mathrm{Cx} 43$ expression. Confluent cells were subcultured regularly. Prior to experimentation, functional gap junctions were determined by using the scrape-loading/dye transfer technique (Table 1) [21]. 


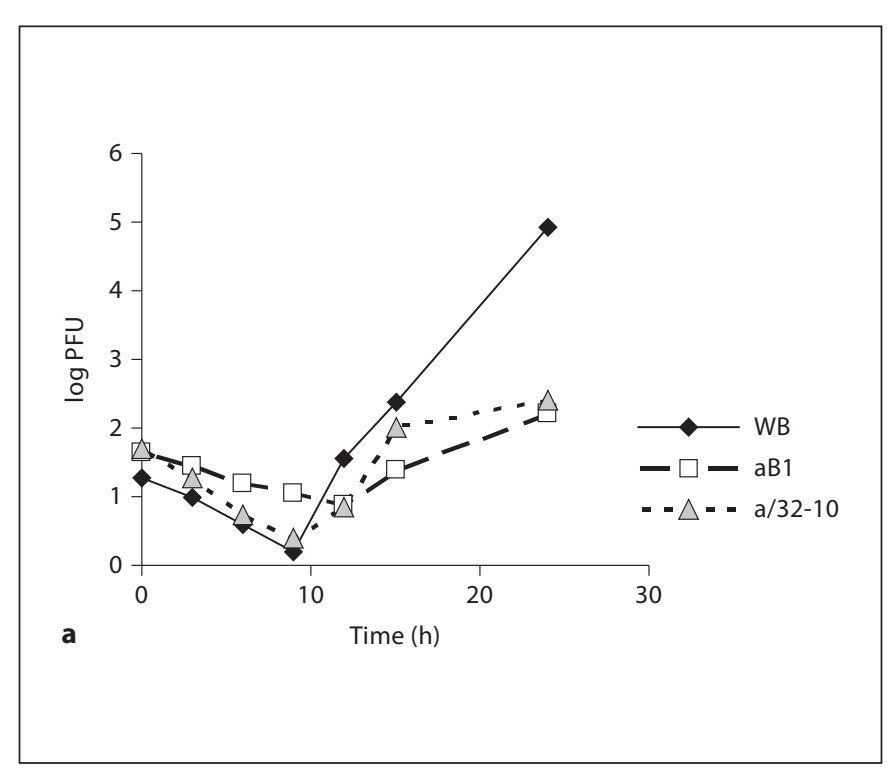

Fig. 1. Growth curves of HSV-2 in mutant WB cells show reduced virus production at later time points compared to wild-type cells. Early (a) and late (b) growth curves of HSV-2 (MOI = 0.01) in WB,

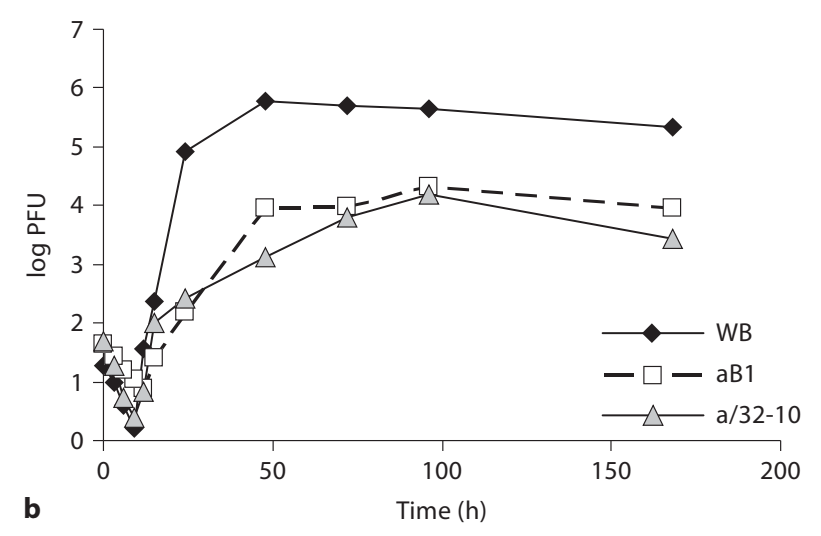

aB1, and a/32-10 cells. At various time points, from $2 \mathrm{~h}$ to 15 days, cells were frozen at $-80^{\circ}$ and later assayed for plaque-forming unit ability (PFU) on WB cells.
HSV-2 Growth Curve in Three Cell Types

$\mathrm{WB}, \mathrm{aB} 1$, and $\mathrm{a} / 32-10$ cells were cultured in $\mathrm{D}$-medium and grown to confluence in $25-\mathrm{cm}^{2}$ culture flasks at $37^{\circ}$. The culture medium was decanted from the flasks and $1 \mathrm{ml}$ of HSV-2 strain G (ATCC, $0.01 \mathrm{MOI}$ ) was added to each experimental flask while culture medium alone was added to control flasks. After $1 \mathrm{~h}$ of incubation at $37^{\circ}$, the virus was removed and replaced with fresh medium. After incubation for $2 \mathrm{~h}$ to 15 days at $37^{\circ}$, cells were frozen for later quantification of viral titers which were determined by plaque assay as described below.

Cell extracts from the three HSV-2-infected cell lines frozen at various time points were subjected to three cycles of freezing and thawing, were centrifuged for $10 \mathrm{~min}$ at 2,000 rpm, and the supernatant samples were frozen in 1-ml aliquots and stored at $-80^{\circ}$. WB cells were then infected with serial dilutions of virus harvested from each cell line and incubated for $36-48 \mathrm{~h}$ at $37^{\circ}$, stained with $1 \%$ crystal violet in $35 \%$ methanol, and analyzed for plaque-forming units.

\section{Indirect Immunofluorescent Labeling}

Cells were grown in twelve well plates until near confluence and, when infected, incubated with herpes simplex virus type-2 (HSV-2 Stain G, ATCC, MOI $=10$ to maximize infection) for $1 \mathrm{~h}$ at $37^{\circ}$ in $5 \% \mathrm{CO}_{2}$. Virus was removed and replaced with medium and plates were incubated for 3-48 h at $37^{\circ}$. Cells were washed twice with cold PBS and fixed with methanol for $20 \mathrm{~min}$ at $-20^{\circ}$. Cells were permeabilized with PBS containing $0.1 \%$ (v/v) Tween 20 (PBT) and blocked for at least 30 min with PBT containing 5\% fetal calf serum (FCS-PBT). Cells were then incubated for at least $2 \mathrm{~h}$ with primary antibody [mouse monoclonal anti-connexin 43, nectin-1, E-cadherin, rabbit ZO-1, $\beta$-catenin (Zymed Laboratories, San Francisco, Calif., USA) and rabbit polyclonal anti-HSV-2, mouse anti-glycoprotein E (Dako Corp., Carpinteria, Calif., USA)] at a dilution of 1:500 in FCS-PBT. Excess antibody was removed by washing plates three times for 5 min each with PBT. Secondary antibodies tagged with AlexaFluor 488 (anti-mouse) and AlexaFluor 546 (anti-rabbit; Molecular Probes, Eugene, Oreg., USA) were added at a dilution of 1:1,000 and incubated at room temperature for at least $1 \mathrm{~h}$ or refrigerated overnight.

\section{Western Blot}

Protein extracts were separated on a $12 \%$ SDS-polyacrylamide gel using a mini-Protein III electrophoresis apparatus (Bio-Rad) run at $100 \mathrm{~V}$. The separated proteins were transferred to PVDF membranes using a mini-Transblot apparatus (Bio-Rad) at $30 \mathrm{~V}$ overnight. The membranes were incubated for at least $2 \mathrm{~h}$ with a mouse anti-E-cadherin antibody $(1: 1,000)$. The bound antibody was detected using an anti-mouse secondary antibody $(1: 1,000)$ conjugated with alkaline phosphatase and visualized with the alkaline phosphatase color development reagents, BCIP (5-bromo4 -chloro-3-indoylphosphate $p$-toluidine salt) and NBT ( $p$-nitroblue tetrazolium chloride).

\section{Infectious-Center Assay}

Modified infectious-center assays were performed as previously described [22]. Briefly, WB and a/32-10 cells (donor cells) in $35-\mathrm{mm}$ plates at $50 \%$ confluence were exposed to virus at $37^{\circ}$ to allow entry $(\mathrm{MOI}=10)$. Cells were washed with citrate buffer $(\mathrm{pH}$ $3.0)$ to inactivate residual extracellular virus $1-2 \mathrm{~h}$ after infection followed by three washes with PBS and subsequent incubation in medium. Then, $5 \mathrm{~h}$ after infection, the infected cells were detached with trypsin-EDTA and counted, and 1,000 cells were plated onto duplicate monolayers of uninfected WB or a/32-10 cells (recipient cells) in medium containing human IgG (Sigma) to 


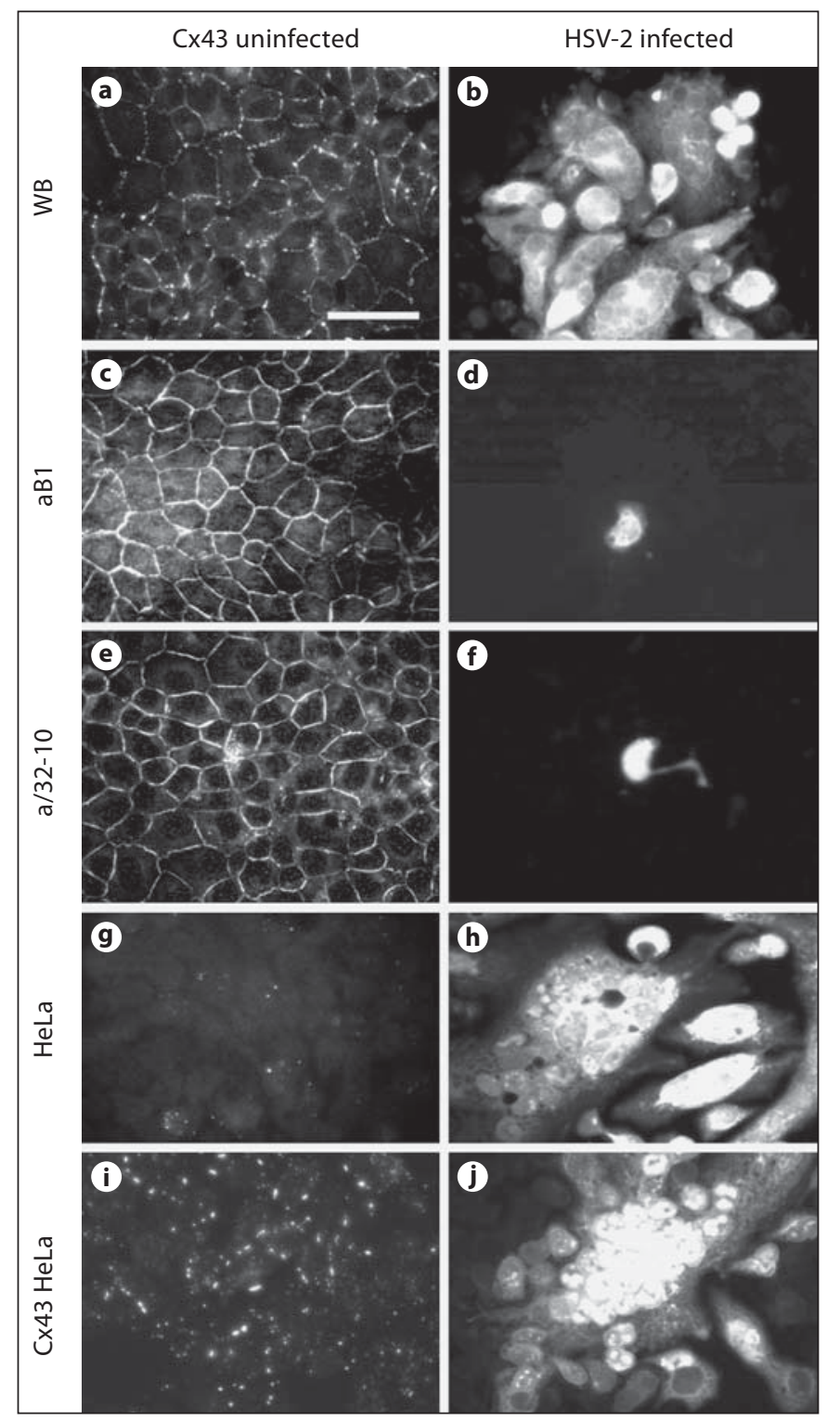

Fig. 2. a-j Cx43 distribution and infection differs among cell types. Indirect immunofluorescent labeling of $\mathrm{Cx} 43$ in uninfected WB (a), aB1 (c), a/32-10 (e), HeLa (g), Cx43-transfected HeLa (i) cells and HSV-2 in infected WB (b), aB1 (d), a/32-10 (f), HeLa (h), and Cx43-transfected HeLa (j) cells 24 h post-infection. Note the punctate distribution of $\mathrm{Cx} 43$ in WB (a) and $\mathrm{Cx} 43$-transfected HeLa (i), the uniform distribution of $\mathrm{Cx} 43$ in aB1 (c) and a/32-10 (e), and the absence of Cx43 in HeLa cells (g). WB, HeLa, and $\mathrm{Cx} 43$-transfected HeLa were permissive to infection with large viral plaques, whereas $\mathrm{aB} 1$ and a/32-10 cells were less permissive with isolated infected cells and absence of cell-to-cell spread (scale bar in $\mathbf{a}=100 \mu \mathrm{m}$ which represents the entire figure). neutralize infection by virus released into the medium. After $48 \mathrm{~h}$, infected cells were visualized using indirect immunofluorescence with anti-HSV-2 as the primary antibody (see Methods).

\section{Microscopy Techniques}

Observations of fluorescent probes were made using an Olympus IX-71 inverted microscope (Olympus America Inc., Melville, N.Y., USA) equipped with epi-illumination fluorescence optics with the proper dichromatic mirrors, excitation filters and barrier filters for visualization of the fluorophores. This microscope was also equipped with an Olympus IX2-DSU spinning disk confocal unit. Images were captured with a Spot Xplorer cooled CCD camera (Diagnostic Instruments Inc., Sterling Heights, Mich., USA), with iVision software (BioVision Technologies Inc., Exton, Pa., USA) running on an Apple Macintosh G-5 computer.

\section{Results}

\section{HSV-2 Growth Was Attenuated in Mutant WB Cells at Later Time Points}

Both GJIC-deficient aB1 cells and GJIC-rescued a/3210 cells produced fewer viruses at later time points compared to WB cells (Fig. 1). Low MOI (0.01) was used in this experiment in order to maintain wild-type WB cell viability for the extended time course. Higher MOI (1.010) resulted in rapid loss of viable WB cells within $72 \mathrm{~h}$. Although the growth curves for all three cell types were similar for the first $12 \mathrm{~h}$ (Fig. 1a), there was at least a 100fold decrease in virus production in the mutant cells at all of the later time points (Fig. 1b). Based on the similarities of the growth curves at early time points, the mutant cells did not prevent viral entry. The production of fewer viruses later in the infection could be due to differences in cell-to-cell spread or virus yield in infected cells.

\section{Cx43 Expression and HSV-2 Infection in}

Communicating and Non-Communicating Cells

The presence and distribution of $\mathrm{Cx} 43$ in the different cell types are demonstrated in Figure 2. While WB cells exhibited punctate distribution of $\mathrm{Cx} 43$ labeling (Fig. 2a), both aB1 and a/32-10 cells showed uniform Cx43 membrane localization (Fig. 2c, e). These results are consistent with previously published studies [6,7]. HeLa cells showed no membrane Cx43 labeling (Fig. 2g), while Cx43-transfected HeLa cells expressed punctuate distribution of $\mathrm{Cx} 43$ in the plasma membrane (Fig. 2i). Although WB, $\mathrm{HeLa}$, and Cx-transfected HeLa cells were highly permissive to HSV-2 and produced large virus plaques (Fig. 2b, $h, j), a B 1$ and a/32-10 cells demonstrated few infected cells with markedly reduced virus spread to adjacent cells (Fig. 2d, f). These results (Table 1) indicate that function- 
Fig. 3. a-i Distribution differences of Cx43, but not ZO-1, among uninfected cell types. Indirect immunofluorescent labeling of Cx43 (red) in uninfected WB (a), aB1 (d), a/32-10 (g) cells; ZO-1 (green) in uninfected WB (b), aB1 (e), a/32-10 (h) cells, and merged images of $\mathrm{Cx} 43$ and ZO-1 (yellow shows co-localization) in uninfected WB (c), aB1 (f), and a/32-10 (i) cells. Note the punctate distribution of $\mathrm{Cx} 43$ in WB (a), the uniform distribution of $\mathrm{Cx} 43$ in aB1 (d) and a/32-10 (g), and the uniform distribution of ZO-1 in all three cell types. All cell types show evidence of co-localization of $\mathrm{Cx} 43$ and ZO-1, although these areas of overlap are fewer in the WB cells due to the punctate distribution of Cx-43 (scale bar in $\mathbf{a}=25 \mu \mathrm{m}$ which represents the entire figure). Colors refer to the online version only.

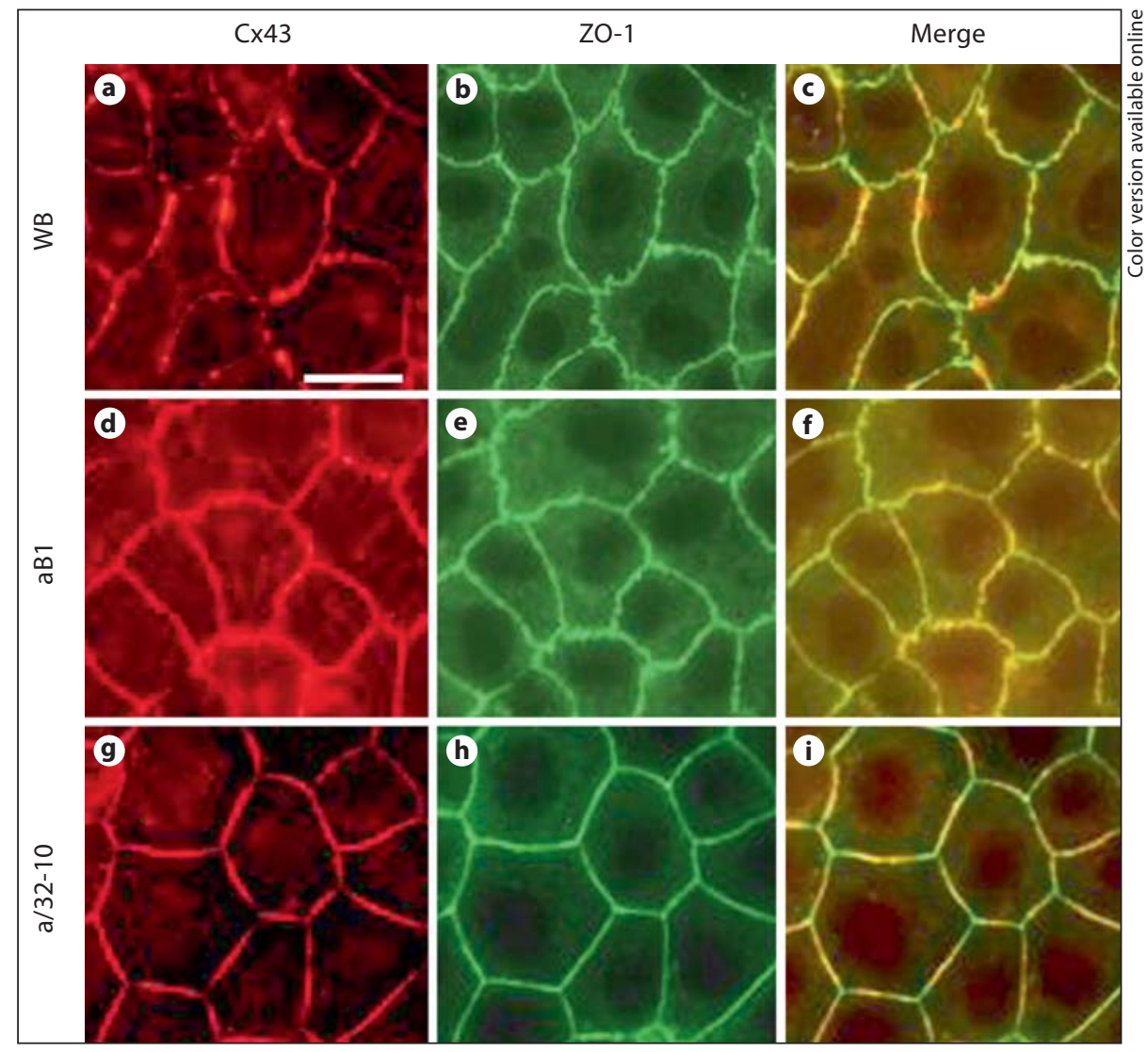

al gap junctions do not increase HSV-2 infectivity and that another factor is responsible for small plaque formation in the communication-deficient (aB1) and communication-rescued (a/32-10) cells.

\section{Distribution of Tight and Adherens Junction Proteins in WB Cell Lines}

The tight junction protein, ZO-1, and adherens junction proteins, nectin-1 and E-cadherin, were evaluated for their cellular localization using indirect immunofluorescence. In contrast to the punctate distribution of $\mathrm{Cx} 43$ found only in wild-type cells, ZO-1 was distributed similarly in the plasma membrane of all three WB cell lines (Fig. 3). Nectin-1, an important adherens junction protein and receptor for HSV-2 infection, also was found similarly distributed in both the plasma membrane and nucleus of all WB cells (data not shown). E-cadherin, however, was absent in the plasma membrane of wildtype cells but present in both aB1 and a/32-10 cells (Fig. 4). A Western blot confirming the different expression of $\mathrm{E}$ cadherin in WB versus $\mathrm{aB} 1$ and $\mathrm{a} / 32-10$ cell lines can be seen in Figure 4g.

Adherens Junction Proteins in

Differential HSV-2 Infectivity

\section{Inhibition of Cell-Cell Spread in Mutant WB Cells}

Infectious-center assays were performed to test the hypothesis that a/32-10 cells (GJIC-rescued) are resistant to infection by preventing cell-to-cell spread. Cultures of infected WB and a/32-10 cells (donor) were trypsinized and overlaid on recipient WB or a/32-10 cells. When infected WB cells were overlaid on recipient WB cells, large viral plaques, visualized using indirect immunofluorescence, were produced (Fig. 5a). In contrast, infected WB cells (donor) added to a culture of uninfected a/32-10 cells led to small, localized areas of infection (Fig. 5b). When infected a/32-10 cells were overlaid on either uninfected WB cells (Fig. 5c) or a/32-10 (Fig. 5d), small, localized areas of infection are evident. The dual observation that both infected WB cells fail to spread virus to uninfected a/32-10 cells and infected a/32-10 cells do not fuse with and spread virus to uninfected WB cells indicate that the intercellular junctions created by local fusion events between the plasma membrane of infected and neighboring uninfected cells do not occur in a/32-10 cells. These results suggest that mutant WB cells demonstrate reduced viral infectivity at later time points by preventing cell-to-cell spread of virus.

Intervirology 2012;55:465-474 
Fig. 4. a-f Mutant WB cells express more membrane E-cadherin compared to wildtype cells. Indirect immunofluorescent labeling of E-cadherin in uninfected WB (a), aB1 (c), a/32-10 (e) cells with merged images of $\mathrm{Cx} 43$ (red) and E-cadherin (green) with co-localization shown in yellow in uninfected WB (b), aB1 (d), and a/32-10 (f) cells. Note the lack of plasma membraneassociated E-cadherin in WB (a) cells compared to aB1 (c) and a/32-10 (e) cells. In $\mathbf{g}$, Western blot demonstrates less Ecadherin in $\mathrm{WB}$ versus $\mathrm{aB} 1$ and $\mathrm{a} / 32-10$ cells. Compared to WB cells, aB1 and a/3210 cell types show evidence of co-localization of $\mathrm{Cx} 43$ and E-cadherin in the plasma membrane (scale bar in $\mathbf{a}=100 \mu \mathrm{m}$ which represents the entire figure). Colors refer to the online version only.
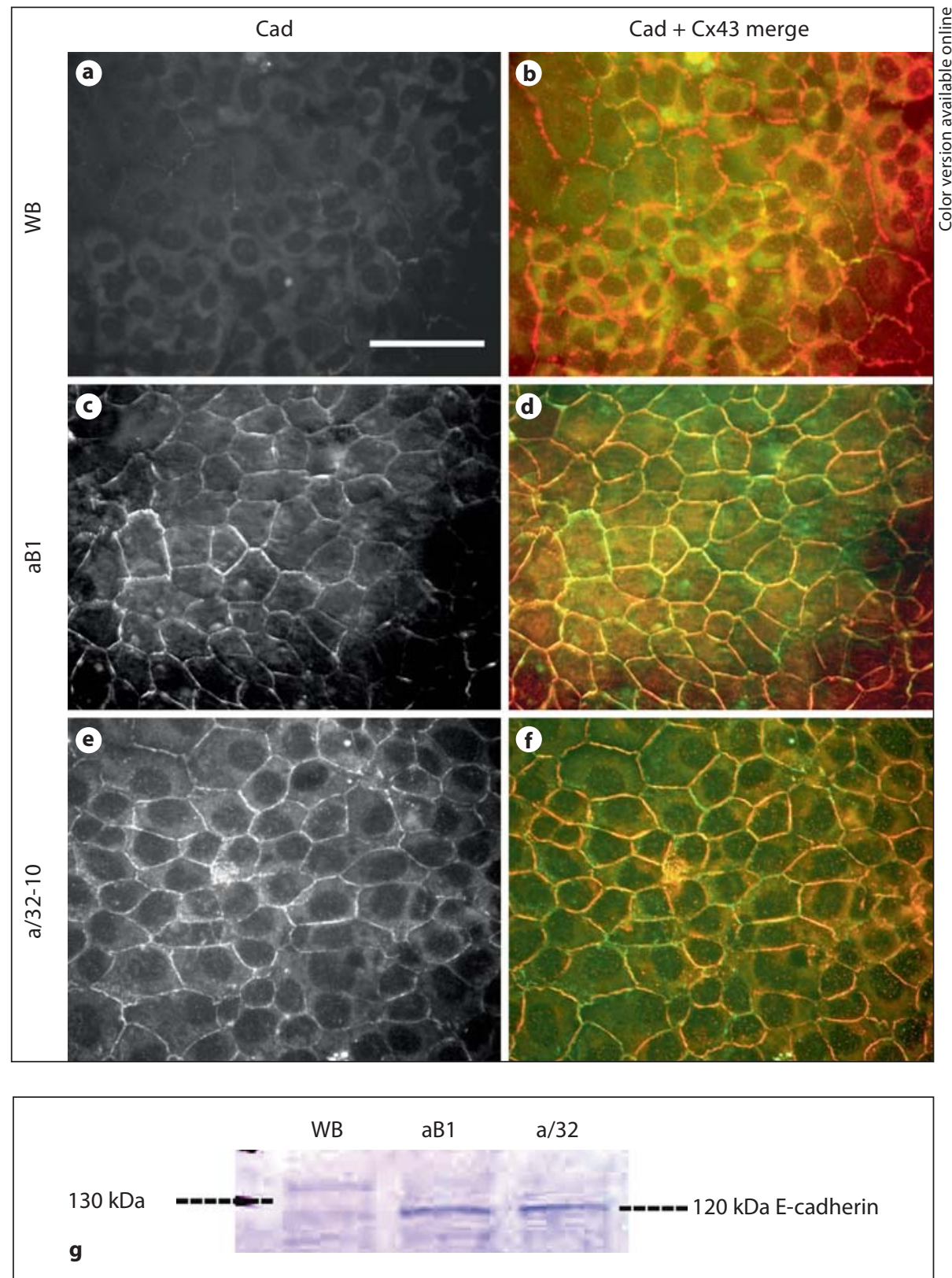

\section{Co-Localization of $\beta$-Catenin with HSV-2}

Glycoprotein E

Due to the plasma membrane localization of E-cadherin and decreased cell-to-cell spread of HSV-2 in mutant WB cells, $\beta$-catenin, a protein associated with Ecadherin, and glycoprotein $\mathrm{E}$ (gE), a protein important for cell-to-cell spread of HSV-2 [23-26], were investigated for their ability to interact with each other in infected cells. As seen in Figure 6a and b, membrane fusion and syncytial formation in infected wild-type WB cells was associated with loss of membrane $\beta$-catenin and no co-localization of $\beta$-catenin with gE. In contrast, mutant WB cells demonstrated co-localization of $\beta$-catenin and $\mathrm{gE}$ in infected cells $48 \mathrm{~h}$ post-infection (Fig. 6d, f).

Table 1 provides a summary of the results highlighting the differences between the cell types with respect to their gap junction proteins, communication, infectivity, and membrane protein distribution. 
Fig. 5. a-d Cell-to-cell spread of HSV-2 is reduced in mutant cells. Infectious-center assay with infected cells labeled via indirect immunofluorescence using antiHSV-2. Infected WB cells served as the donor cells in $\mathbf{a}$ and $\mathbf{b}$ while infected $\mathbf{a} / 32-10$ cells were the donor cells in $\mathbf{c}$ and $\mathbf{d}$. In $\mathbf{a}$, infected $\mathrm{WB}$ donor cells were seeded onto uninfected, recipient WB cells, while in $\mathbf{b}$, infected WB cells were seeded onto uninfected, recipient a/32-10 cells. In c, infected a/32-10 cells were seeded onto uninfected WB cells, while in $\mathbf{d}$, infected a/32-10 cells were seeded onto uninfected a/32-10 cells. Note the large infected area in a, but small, punctuate infected areas in $\mathbf{b}, \mathbf{c}$, and $\mathbf{d}$ (scale bar in $\mathbf{a}=100 \mu \mathrm{m}$ which represents the entire figure).

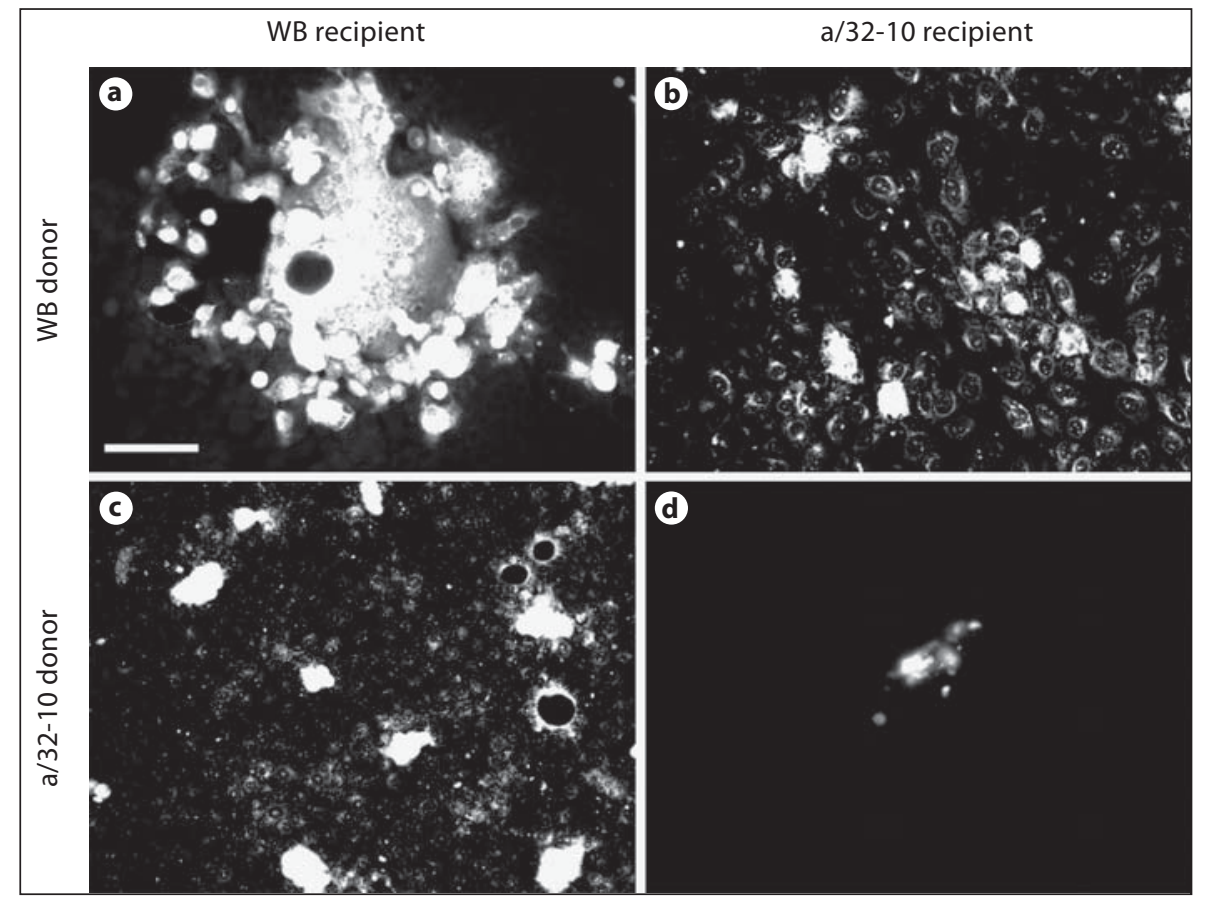

\section{Discussion}

Loss of functional gap junctions following infection may serve as a cellular protective mechanism to limit viral spread. Previous studies have demonstrated that, by $3 \mathrm{~h}$ post-infection and before morphological changes take place, GJIC was attenuated in HSV-2 infected Vero cells [14]. In addition, $\mathrm{Cx} 43$ was lost from the plasma membrane at $24 \mathrm{~h}$ post-infection [16].

In an attempt to elucidate the relationship, if any, between functional gap junctions and HSV-2 infectivity, we compared HSV-2 growth in WB cells and in a GJIC-deficient mutant, WB-aB1. WB-aB1 cells were markedly more resistant to HSV-2 infection compared to wild-type WB cells. In WB-a/32-10 cells, restoring GJIC by transfection with the alternate gap-junction protein $\mathrm{Cx} 32 \mathrm{did}$ not reverse the resistant phenotype of aB1 cells (Table 1). Although the mechanism responsible for the loss of communication in aB1 cells is not known [J. Trosko, pers. commun.], we also found that communication-deficient HeLa cells and HeLa transfected with Cx43 were equally permissive to HSV-2. The combination of these results and the lack of a direct relationship between $\mathrm{Cx} 43$ or GJIC and infectivity led us to investigate other gap junction-associated proteins to explain the different infectivity in WB cells.
The formation of functional gap junctions depends on the presence of tight and adherens junctions, making intercellular junctional proteins an important component of cellular communication [27]. Tight junction proteins, such as zonula occludens-1 (ZO-1), tether transmembrane proteins to the actin cytoskeleton and a growing number of connexins can associate with $\mathrm{ZO}$ proteins to organize gap junctions and/or regulate intercellular communication $[26,28]$. Despite the important role in communication played by ZO-1, no difference in ZO-1 distribution was found in wild-type versus mutant WB cells in the present study.

Adherens junctions mediate adhesion between cells by linking the actin cytoskeleton of one cell to that of the next cell via transmembrane adhesion proteins and their associated protein complexes, such as the nectin/afadin and cadherin/catenin complexes [27]. A recent review by Gonzalez-Mariscal et al. [29] highlights the importance of adherens junctions in viral entry and spread. Nectins serve not only as cellular entry receptors for HSV [30], but also as mediators of the viral cell-to-cell spread [24]. In this study, no difference in nectin-1 distribution was found between wild-type and mutant WB cells, suggesting that another membrane-associated protein was responsible for differences in infectivity.

The importance of nectin-1 for HSV infectivity and its interaction with cadherin led us to investigate variations 
Fig. 6. a-f $\beta$-Catenin and gE co-localize in mutant cells. Indirect immunofluorescent labeling of $\beta$-catenin (red) in infected WB (a), aB1 (c), or a/32-10 (e) cells with merged images of $\beta$-catenin and $g E$ (green) in infected WB (b), aB1 (d), and a/32-10 (f) cells $48 \mathrm{~h}$ post-infection. Note the loss of $\beta$ catenin in the plasma membrane and lack of co-localization of $\mathrm{gE}$ and $\beta$-catenin in infected WB cells compared to co-localization of $\mathrm{gE}$ and $\beta$-catenin (yellow) in infected aB1 (c) and a/32-10 (e) cells (scale bar in $\mathbf{a}=100 \mu \mathrm{m}$ which represents the entire figure). Colors refer to the online version only.

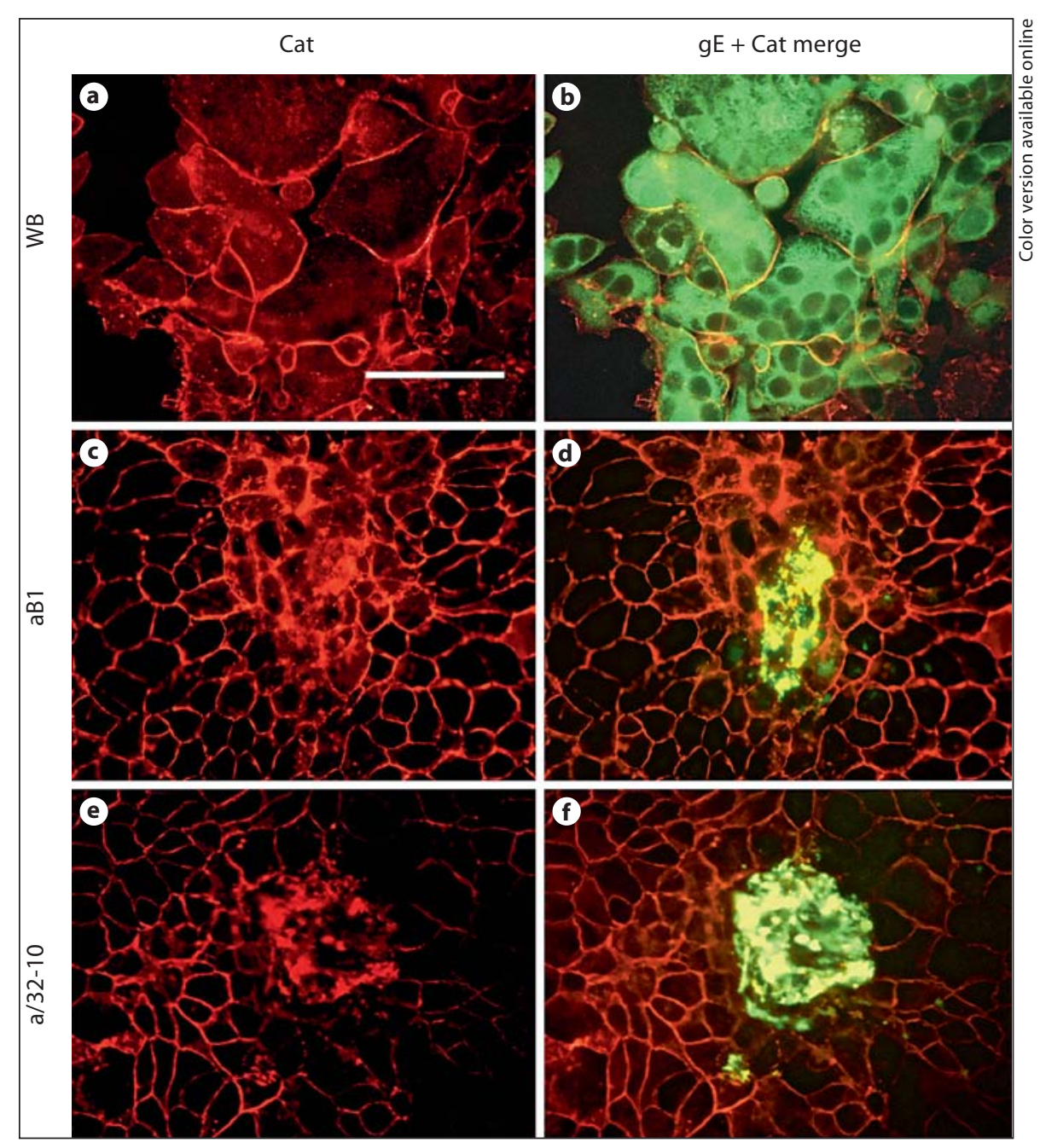

in cadherin levels and distribution in WB cells. Both aB1 and a/32-10 cells demonstrated greater protein content and plasma membrane distribution of cadherin compared to wild-type cells. Cadherins comprise an important family of transmembrane glycoproteins that mediate calcium-dependent cell-cell adhesion, are linked to the actin cytoskeleton via catenins, and serve as docking sites for gap junctions [31]. Meyer et al. [32] observed in Novikoff cells that antibodies directed against either the extracellular domain of $\mathrm{Cx} 43$ or $\mathrm{N}$-cadherin prevented both gap junction and adherens junction formation. In $\mathrm{aB} 1$ and a/32-10 cells, the uniform distribution of E-cadherin in the plasma membranes may be responsible for the even pattern of $\mathrm{Cx} 43$ distribution in uninfected cells.

Our results from both the growth curves and the infectious-center assay suggest that the decreased HSV infectivity in mutant WB cells is due to attenuated viral spread. The viral glycoproteins, gE and gI, mediate viral spread though interactions with junctional proteins [23$25,33]$. Since cadherin was absent from the plasma membrane in wild-type WB cells, we investigated the ability of $\beta$-catenin, another $\mathrm{AJ}$ protein that associates with cadherin [34], to mediate virus spread in infected WB cells. After $48 \mathrm{~h}$ post-infection, $\beta$-catenin and $\mathrm{gE}$ remained colocalized in infected $\mathrm{aB} 1$ and $\mathrm{a} / 32-10$ cells but not in wildtype cells. Co-localization of $\mathrm{gE}$ and $\beta$-catenin at membrane junctions was found in previous studies [24] but only after $11 \mathrm{~h}$ of infection with wild-type HSV-1 [35]. In addition, Wisner et al. [36] showed that plaque formation and cell-to-cell spread by an $\mathrm{HSV}_{\mathrm{gE}} \mathrm{gE}^{-}$mutant depended on whether the cells possessed extensive junctions. In a later study, Farnsworth and Johnson [25] found different plaque sizes, $\beta$-catenin distribution and trafficking of $\mathrm{gE} /$ gI to cell junctions depending on whether they used hu- 
man keratinocytes (HaCaT) or retinal epithelial (ARPE19) cells. They observed greater co-localization of mutant $\mathrm{gE}$ with cytoplasmic $\beta$-catenin in ARPE-19 cells which was associated with smaller plaque size [25]. In the present study, decreased cell-to-cell spread of wild-type HSV2 in mutant WB cells was associated with the presence of plasma membrane cadherin and co-localization of $\mathrm{gE}$ and $\beta$-catenin $48 \mathrm{~h}$ following infection. These results suggest that, compared to wild-type cells, mutant WB cells possess a mutation that permits tighter association between $\mathrm{gE}$ and $\beta$-catenin which prevents cell-to-cell spread.

In summary, HSV-2 infection causes loss of functional gap junctions and plasma membrane $\mathrm{Cx} 43$ in wild-type WB cells early in infection, but the ability of virus to infect cells is not directly dependent on the presence of functional gap junctions or $\mathrm{Cx} 43$. Mutant WB cells show altered infectivity characterized by deficient cell-to-cell spread that is associated with increased membrane cadherin and co-localization of $\mathrm{gE}$ and $\beta$-catenin following long periods of infection. These cells could serve as useful tools for identifying cellular genes that are required for virus fusion events and the interaction of viral gene products with membrane proteins. In addition, treatments that target adherens junction interactions with viral proteins should be investigated as a novel mechanism to attenuate HSV-2 cell-to-cell spread.

\section{Acknowledgements}

The authors would like to thank Geraldine Misquith and Radhika Bhatt for technical support. West Chester University graduate student research awards to B.M. and K.M.K. were used to support this project as well as an NIH AREA grant (1 R15 AI05552401) to R.W., G.M. and M.K.

\section{References}

1 Loewenstein WR: Junctional intercellular communication: the cell-to-cell membrane channel. Physiol Rev 1981;61:828-913.

-2 Beyer EC, Paul DL, Goodenough DA: Connexin family of gap junction proteins. J Membr Biol 1990;116:187-194.

>3 Schwarzmann G, Wiegandt H, Rose B, Zimmerman A, Ben-Haim D, Loewenstein WR: Diameter of the cell-to-cell junctional membrane channels as probed with neutral molecules. Science 1981;213:551-553.

4 Cieniewicz AM, Woodruff RI: Passage through vertebrate gap junctions of $17 / 18 \mathrm{kDa}$ molecules is primarily dependent upon molecular configuration. Tissue Cell 2010;42: 47-52.

5 Caspar DLD, Sosinski GE, Tibbitts TT, Phillips WC, Goodenough DA: Gap junction structure; in Hertzberg EL, Johnson RG (eds): Gap Junctions. New York, Liss, 1988, pp 117-133.

-6 Beyer EC, Kistler J, Paul DL, Goodenough DA: Antisera directed against $\mathrm{Cx} 43$ peptides react with a $43-\mathrm{kDa}$ protein localized to gap junctions in myocardium and other tissues. J Cell Biol 1989;108:595-605.

7 Oh SY, Dupont E, Madhukar BV, Briand JP, Chang CC, Beyer E, Trosko JE: Characterization of gap junctional communicationdeficient mutants of a rat liver epithelial cell line. Eur J Cell Biol 1993;60:250-255.

$>8$ Dunham LJ, Stewart HL: A survey of transplantable and transmissible animal tumors. J Nat Cancer Inst 1953;13:1299-1377.
9 Pitts JD: Molecular exchange and growth control in tissue culture; in Wolstenholme GEN, Knight J (eds): Growth Control in Cell Cultures. New York, Churchill-Livingston, 1971, pp 89-105.

10 Musil LS, Cunningham BA, Edelman GM, Goodenough DA: Differential phosphorylation of the gap junction protein connexin 43 in junctional communication-competent and -deficient cell lines. J Cell Biol 1990;111: 2077-2088.

11 Musil LS, Goodenough DA: Biochemical analysis of connexin 43 intracellular transport, phosphorylation, and assembly into gap junctional plaques. J Cell Biol 1991;115: 1357-1374.

12 De Mello WC: Cyclic nucleotides and junctional permeability; in Hertzberg EL, Johnson RG (eds.): Gap Junctions. New York, Liss, 1988, pp 245-254.

13 Atkinson MM, Sheridan JD: Reduced junctional permeability in cells transformed by different viral oncogenes; in Bennett MVL, Spray DC (eds): Gap Junctions. New York, Cold Spring Harbor Laboratory, 1985, pp 205-213.

14 Fischer NO, Mbuy GNK, Woodruff RI: HSV2 disrupts gap junctional intercellular communication between mammalian cells in vitro. J Virol Methods 2001;91:157-166.

15 Musee J, Mbuy GNK, Woodruff RI: Antiviral agents alter ability of HSV-2 to disrupt gap junctional intercellular communication between mammalian cells in vitro. Antiviral Res 2002;56:143-151.
16 Knabb MT, Danielsen CA, McShane-Kay K, Mbuy GKN, Woodruff RI: Herpes simplex virus-type 2 infectivity and agents that block gap junctional intercellular communication. Virus Res 2007;124:212-219.

17 Stanton RJ, McSharry BP, Rickards CR, Wang ECY, Tomasec P, Wilkinson GWG: Cytomegalovirus destruction of focal adhesions revealed in a high-throughput Western blot analysis of cellular protein expression. J Virol 2007;81:7860-7872.

18 Rae RS, Mehta PP, Chang CC, Trosko JE, Ruch RJ: Neoplastic phenotype of gap-junctional intercellular communication-deficient WB rat liver epithelial cells and its reversal by forced expression of connexin 32 . Mol Carcinog 1998;22:120-127.

19 Elfgang C, Eckert R, Lichtenberg-Frate H, Butterweck A, Traub O, Klein RA, Hulser DF, Willecke K: Specific permeability and selective formation of gap junction channels in connexin-transfected HeLa cells. J Cell Biol 1995; 129:805-817.

-20 Tsao MS, Smith JD, Nelson KG, Grisham JW A diploid epithelial cell line from normal adult rat liver with phenotypic properties of 'oval' cells. Exp Cell Res 1984;154:38-52.

21 El-Fouly MH, Trosko JE, Chang CC: Scrapeloading and dye transfer. A rapid and simple technique to study gap junctional intercellular communication. Exp Cell Res 1987;168: 422-430. 
22 Roller RJ, Herold BC: Characterization of a $\mathrm{BHK}\left(\mathrm{TK}^{-}\right)$cell clone resistant to post-attachment entry by herpes simplex virus types 1 and 2. J Virol 1997;71:5805-5813.

23 Collins WJ, Johnson DC: Herpes simplex virus gE/gI expressed in epithelial cells interferes with cell-to-cell spread. J Virol 2003;77: 2686-2695.

24 Dingwell KS, Johnson DC: The herpes simplex virus gE-gI complex facilitates cell-tocell spread and binds to components of cell junctions. J Virol 1998;72:8933-8942.

-25 Farnsworth A, Johnson DC: Herpes simplex virus $\mathrm{gE} / \mathrm{gI}$ must accumulate in the transGolgi network at early times and then redistribute to cell junctions to promote cell-cell spread. J Virol 2006;80:3167-3179.

-26 Johnson RG, Meyer RA, Li XR, Preus DM, Tan L, Grunenwald H, Paulson AF, Laird DW, Sheridan JD: Gap junctions assemble in the presence of cytoskeletal inhibitors, but enhanced assembly requires microtubules. Exp Cell Res 2002;275:67-80.
7 Derangeon M, Spray DC, Bourmeyster N, Sarrouilhe D, Hervé JC: Reciprocal influence of connexins and apical junction proteins on their expressions and functions. Biochim Biophy Acta 2009;1788:768-778.

28 Hervé JC, Bourmeyster N, Sarrouilhe D, Duffy HS: Gap junctional complexes: from partners to functions. Prog Biophys Mol Biol 2007;94:29-65.

29 Gonzalez-Mariscal L, Garay E, Lechuga S: Virus interaction with the apical junctional complex. Front Biosci 2009;14:731-768.

30 Yoon M, Spear PG: Disruption of adherens junctions liberates nectin-1 to serve as receptor for herpes simplex virus and pseudorabies virus entry. J Virol 2002;76:7203-7208.

31 Shaw R, Fay A, Puthenveedu M, von Zastrow M, Jan Y, Jan L: Microtubule plus-end-tracking proteins target gap junctions directly from the cell interior to adherens junctions. Cell 2007;128:547-560.
32 Meyer RA, Laird DW, Revel JP, Johnson RG: Inhibition of gap junction and adherens junction assembly by connexin and A-CAM antibodies. J Cell Biol 1992;119:179-189.

-33 Johnson DC, Webb M, Wisner TW, Brunetti C: Herpes simplex virus gE/gI sorts nascent virions to epithelial cell junctions, promoting virus spread. J Virol 2001;75:821-833.

34 Shapiro L, Weis WI: Structure and biochemistry of cadherins and catenins. Cold Spring Harb Perspect Biol 2009;1: a003053.

- 35 McMillan TN, Johnson DC: Cytoplasmic domain of herpes simplex virus gE causes accumulation in the trans-Golgi network, a site of virus envelopment and sorting of virions to cell junctions. J Virol 2001;75:19281940.

36 Wisner T, Brunetti C, Dingwell K, Johnson DC: The extracellular domain of herpes simplex virus $\mathrm{gE}$ is sufficient for accumulation at cell junctions but not for cell-to-cell spread. J Virol 2000;74:2278-2287. 